\title{
Determinants of Knowledge Transfer in Egocentric Networks. Comparative Analysis of Professions
}

\author{
MARZENA FRYCZYŃSKA \\ Collegium of Business Administration \\ Warsaw School of Economics \\ Al. Niepodległości 162, 02-554 Warsaw \\ POLAND
}

\begin{abstract}
This paper investigates determinants of knowledge transfer in egocentric networks of knowledge recipient and knowledge provider, what is crucial to knowledge management in organisations. Knowledge transfer is assumed to depend on knowledge work, networking competence, and the subject's profession: teacher, Information Technology (IT) professional, or physician. The paper reports result of a quantitative study among samples of mentioned professionalists. Regression models testing, including mediation and moderation, were performed. The findings indicate that knowledge transfer in the egocentric network of the knowledge recipient increases along with knowledge work, but only when it is mediated by networking competence. Analyses in each profession support a partial mediation in the case of IT professionals and teachers. Knowledge transfer in egocentric network of the knowledge provider increases along with knowledge work of the provider. In the case of physicians, knowledge transfer in the providers' and recipients' knowledge networks is affected neither by knowledge work nor by networking competence.
\end{abstract}

Key-Words: - knowledge transfer, egocentric network, knowledge network, knowledge provider, knowledge recipient, knowledge work, networking competence

Received: May 23, 2021. Revised: December 14, 2021. Accepted: January 2, 2022. Published: January 3, 2022.

\section{Introduction}

Companies and economies are faced with a challenge of knowledge transfer necessary to run business, achieve goals and develop communities. Knowledge transfer appears among and between organizations, network organizations and its employees. An aim of the present paper is to elaborate knowledge transferred by highly competent professionals in their egocentric networks.

In egocentric networks, predefined ego-an employee, provides or receives flows of knowledge to or from others [55]. This kind of egocentric knowledge networks are differed based on the ego's roles as - a knowledge recipient i.e., receiving others knowledge or - a knowledge provider delivering own knowledge to others. Literature provides numerous examples of factors that affect knowledge transfer dynamics between knowledge providers and recipients e.g., motivation, learning process, existing relationship, level and kind of expertise, trust, or status $[33 ; 67 ; 35 ; 34]$. In the context of egocentric knowledge network, knowledge work is a prominent variable which characterise knowledge recipients and providers, which affects their network size what in turn determine knowledge transfer. According to literature reports, the extent of knowledge transfer between individuals depends on their degree of acquaintance and access to the other person, all of which is supported by their networking competence, understood as the establishment and maintenance of contacts required for one's work.

Despite knowledge workers are active at labour market for decades $[19 ; 20 ; 3]$, nowadays knowledge intensive companies as well as developing economies are in a need of them. The present paper provides a comparative analysis of three selected professions: physicians, IT professionals, and teachers, typically considered as knowledge workers $[16 ; 42]$, with a view to identifying the differences in knowledge transfer in egocentric knowledge networks based on knowledge work and networking competence.

The research problem can therefore be formulated in the following question: How does knowledge transfer in egocentric networks of knowledge providers and recipients who work as physicians, IT professionals, or teachers change based on their knowledge work and networking competence levels? This question is answered in the main body of the paper. The analyses are supported by three detailed questions: 
How does knowledge transfer occur in egocentric networks?

How do knowledge work and networking competence differentiate knowledge transfer in the egocentric networks of the knowledge provider and the recipient?

How does knowledge transfer differ in egocentric networks of physicians, IT professionals, and teachers?

Based on these reflections, two research models and hypotheses were developed to illustrate the associations between independent variables that affect the egocentric networks of knowledge providers and recipients who are physicians, IT professionals, or teachers. In the following study, these research questions and hypotheses are explored and explained based on the analysis of data collected in the quantitative study. Finally, conclusions from the analysis are presented, and the resulting scientific contribution is described, along with possible limitations and indications for future research.

\section{Problem Formulation}

\subsection{Knowledge Transfer in Egocentric Knowledge Networks}

In a broad sense, a network is a ,set of actors and ties among them" [64], where actors are human or nonhuman. The ties are the result of a relationship which emerges from an exchange between the actors. Network types include knowledge networks and exchange networks $[7 ; 29]$. A knowledge network is defined as an organisational system responsible for work processes and the maintenance of organisational knowledge $[62 ; 54]$; a structural representation of accumulated resources of rules, procedures, practices, or documents produced by the joint efforts of former and current employees [63], connected by a network of relationships [51]. In the present paper, knowledge networks are analysed from an egocentric [43] and personal [25] perspective. This means that the main focus of the investigation is an egocentric knowledge network in which an individual employee and their ties to others with whom they transfer knowledge.

In knowledge management people rely on other people when they need to obtain knowledge [8], necessary for quick problem-solving and ongoing work-related task performance $[52 ; 12]$. To perform their work-related tasks, individuals exchange highquality, innovative [41], diverse and unique knowledge, solve problems and seek innovative solutions [9; 27] They exchange knowledge with colleagues from departments of the same organisation $[17 ; 35 ; 9]$, with other organisations in the network [15], and with other individuals in their own contact network, some of whom are boundary spanners [38].

Knowledge transfer, rather than knowledge sharing [45], is assumed here, considering that "transfer" involves a purposeful exchange and a recipient capable of utilising the obtained knowledge [30]. Knowledge is transferred when the knowledge provider decides to share their knowledge, and the recipient accepts it [60]. which is especially likely to occur when the recipient needs the knowledge and such circumstances exist in advice networks [56]. The purposeful nature of knowledge exchange results from organisational standards and workflows or from short-term needs, which can arise when individuals solve problems and challenges in their work.

Knowledge transfer between two individuals exposes two roles: that of a recipient and that of a provider. The recipient is the target node of the relationship, receiving the object of exchange (i.e. knowledge), while the provider is the source node of the relationship, sharing the object of exchange. Networks of associations are seldom evenly distributed [49], which also applies to the egocentric networks of knowledge providers and recipients, even when the same individual alternates between the roles of a provider and a recipient.

Those who need knowledge i.e., potential recipients, first reach out to contacts perceived as able to provide knowledge and inform about other sources of knowledge in a way suited to the recipient's knowledge absorbing capacity [9]. Individuals from whom one seeks knowledge are not chosen at random [5], but rather based on a combination of opportunities, pre-existing relationship, proximity, trust, or familiarity with the advisor [35; 28; $9 ; 57]$. Basically, to provide knowledge, one must have it [13]. Knowledge resources increase along with individuals' education level and professional experience [24]. Involvement in provision of advice increases if one is recognised by a specific community as an expert [17] with a high status [33], which the knowledge provider can achieve through networking.

Therefore, knowledge transfer occurs in the egocentric network of the knowledge recipient when the individual (ego) obtains knowledge from others (providers), and in the egocentric network of the knowledge provider when the employee (ego) provides knowledge to others. 


\subsection{Determinants of Knowledge Transfer in the Egocentric Networks of Knowledge Providers and Recipients}

Knowledge transfer increases as the egocentric networks of knowledge providers and recipients grow. The more contacts the ego has and exchanges knowledge resources with, the more intense the knowledge transfer. Knowledge transfer in the egocentric networks of knowledge providers and recipients grows depending on knowledge work and networking competence, but the impact of these two variables differs between these two types of networks.

The main determinant of intensive knowledge transfer in networks is the performance of knowledge work [10], i.e., work that requires diverse knowledge which is not readily available. Through this work, performed under conditions of autonomy, knowledge workers create innovative solutions that increase their knowledge resources. Nonetheless, the impact of knowledge work differs depending on whether the individual obtains knowledge from others or provides knowledge to them.

The need to perform knowledge work increases the demand for super-networks of contact networks, especially ones that enable access to knowledge that is in short supply [31]. Research by Gargiulo et al. [23] indicates that being a recipient and obtaining knowledge is more beneficial, as knowledge acquisition in close networks increases the value of financial bonuses, while knowledge provision to others decreases this value. As indicated by Brennecke and Rank [9], Research and Development department employees who hold the most patents and have unique knowledge, i.e. those who perform the most knowledge work, seek knowledge from others more often than provide it to them. Thus, having knowledge and creating new knowledge in the innovation process, which is a component of knowledge work, is associated with seeking knowledge from others and acting as a recipient in knowledge networks. Knowledge seeking is intensified by the need to continuously update one's knowledge, especially among individuals working in knowledge-intensive sectors and/or performing knowledge work.

Available research suggests that knowledge transfer towards an individual is possible and indeed desirable even if that individual performs knowledge work, though it is not necessarily strong, as knowledge acquisition also depends on characteristics and competences enabling the employee to successfully reach sources of knowledge.

Another variable that affects egocentric networks is networking competence, understood as the establishment and maintenance of contacts required for one's work. It is a set of workers' behaviours which are stable at a given moment and allow them to gather contacts who can support them with resources. Specific behaviours (or the lack thereof) determine whether a relationship can be established, and how it is developed, maintained, or terminated $[22 ; 66]$. Activity in this area, undertaken in personal on remote contact, directly affects the extent and type of one's direct and dual relationships with each of one's alters. Networking competence is assumed to intensify networks of any type, and its impact on egocentric knowledge networks is based on the assumption that behaviours shape the structure of networks [1], including knowledge networks. Strong networking competence is developed through interactions with others and through the exchange of resources, which over time builds trust and further increases exchange between partners.

Firstly, networking competence helps grow the egocentric network of the knowledge recipient. Through specific behaviours, one establishes and maintains contact with those who can provide access to resources or to other actors. And as it is knowledge that constitutes the object of exchange, networking competence also has an indirect impact, mediated through knowledge work.

Secondly, networking competence helps grow the provider's network as well, and consequently increases the scope of knowledge that is being provided. Even if the establishment of contacts for the provision of knowledge is secondary, the maintenance of contacts is of primary importance. The latter involves behaviours that allow for maintaining a network through exchange between partners, i.e. providing advice and knowledge to others, as well as exchanges understood in the broader context of the social exchange theory [33]. The strength of knowledge transfer from the individual playing the role of a provider largely depends on the quality of their knowledge work. Those who have and create knowledge, and thus perform high-quality knowledge work, are very good contacts for knowledge seekers [17] and hold a valuable transferable resource. In contrast to the model developed for the egocentric networks of knowledge recipients, in the providers' egocentric networks, the impact of networking competence is weaker. Top knowledge workers are not always 
interested in establishing contacts and undertaking networking behaviours [16], and they prefer taskcentred contact networks to social ones [53], consistently with the weaker role of networking competence, which does include socialising [22]. Establishing and maintaining contacts increases one's ability to reach potential knowledge recipients, but only if one has knowledge that is in demand.

For both knowledge transfer models, in the egocentric network of the knowledge recipient or provider, knowledge work is assumed to positively affect networking competence, as knowledge workers are required to regularly participate in knowledge networks [61] and develop relationships that allow network actors to use one another's knowledge resources [5].

The performance of knowledge work enhances networking competence, as the increasing specificity of knowledge work entails the need to establish and maintain contacts with individuals capable of providing support in this work. Greater networking competence also enables the implementation of the personalisation strategy, which is preferred by knowledge workers [26]. The association between knowledge work and networking competence is particularly relevant for contract workers, as going beyond their immediate surroundings allows them to access more diverse knowledge resources and build their identity, based on knowledge, in a variety of contacts [21].

In the present study, the first assumption is that knowledge transfer in the egocentric networks of knowledge recipients and providers is positively correlated with knowledge work and networking competence, as described above. Another assumption is that each of the three studied professions moderates the strength of the hypothesised dependencies, as shown below.

Personal egocentric knowledge networks, their variability, and their impact have been studied in various areas, e.g., Research and Development units [9; 28], and in various professions, e.g., judges [33] physicians [35; 17; 11] school principals [48], teachers [40], or IT professionals [41].

Okkonen et al. [40] reported that physicians benefited from being in a broad network. Still, the study by Mascia et al. [35] demonstrated that physicians tend to be involved in exchange networks with other physicians who have similar knowledge and work in their close environment, with relationships based on reciprocity. Considering a broader range of medical professions, empirical evidence indicates that they are more likely to provide knowledge if they have more social capital [67], but on the other hand, an ego's egocentric network may include alters who will exchange virtually any resource with the ego, or ones who will only exchange selected resources, including knowledge and advice [11]. For teachers, broad networks that allow them to provide and obtain information are the most beneficial [40]. School principals seek advice in their closest environment, among individuals with a similar status, and ones they personally value, regardless of the performance of the schools they manage. They are also more likely to respond to requests for advice than share knowledge unprompted [48]. IT professionals obtain valuable knowledge in strong knowledge networks, through face-to-face communication, and in diverse knowledge networks involving remote communication. The form of communication is not relevant for obtaining diverse knowledge from diverse knowledge networks - if an IT professional belongs to one, they immediately gain more diverse knowledge, and increase their own innovativeness [41].

The cited findings demonstrate specific characteristics of certain professions in terms of knowledge provider and recipient networks. There is, however, no research using the same methodology to compare knowledge networks and their variability between three selected professions, which makes it difficult to formulate specific hypotheses. One could expect that IT professionals have the broadest capabilities of providing and obtaining knowledge in networks. Nonetheless, further studies are needed.

Assuming the potential variation of physicians', IT professionals', and teachers' knowledge networks, the main hypotheses were formulated regarding knowledge transfer in their egocentric networks of knowledge recipient (HI) and provider (HII).

HI Knowledge transfer in the egocentric network of the knowledge recipient increases along with the level of knowledge work they perform, with a strong impact of the mediating networking competence, and is moderated by profession.

HII Knowledge transfer in the egocentric network of the knowledge provider increases along with the level of knowledge work they perform, with a weak impact of the mediating networking competence, and is moderated by profession.

The dependency model with the main and supporting hypotheses of model I and II is shown in Figure 1. 


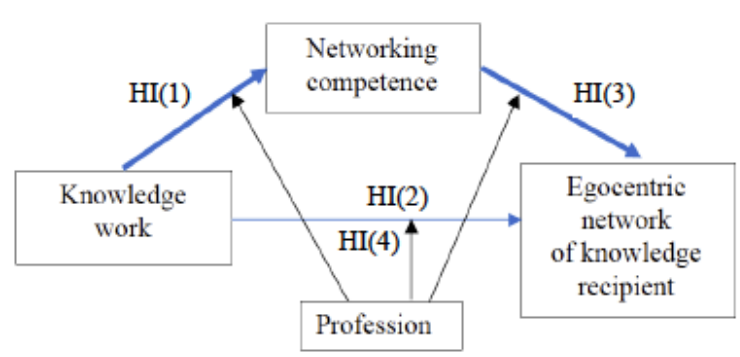

Research model II

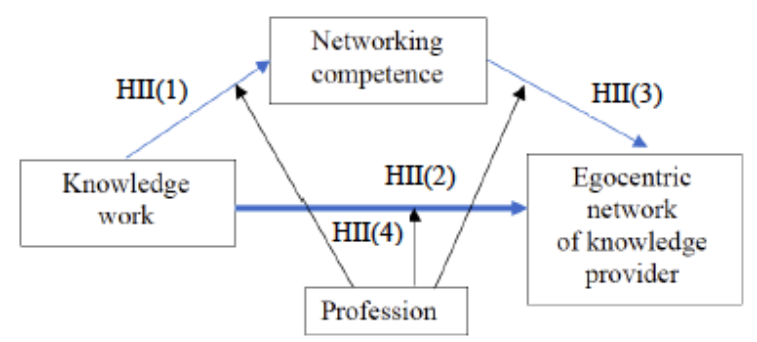

Fig.1: Research models: knowledge transfer in the egocentric networks of the knowledge recipient (I) and the knowledge provider (II)

Research model I

$\mathrm{HI}$ is detailed by supporting hypotheses assuming impacts of knowledge work on networking competence (strong) HI (1), on the size of the egocentric network of the knowledge recipient (moderate) HI (2), and of networking competence on the size of this egocentric network (strong) HI (3). Another supporting hypothesis states that the size of the egocentric network of the knowledge recipient increases along with the level of knowledge work, partially mediated by networking competence HI (4). HII is also detailed by supporting hypotheses assuming impacts of knowledge work: on networking competence (moderate) HII (1), on the size of the egocentric network of the recipient of knowledge (strong) HII (2), and of networking competence on the size of this egocentric network (moderate) HII (3). The final supporting hypothesis assumes that the size of the egocentric network of the knowledge provider increases along with the level of knowledge work, partially mediated by networking competence HII (4). All supporting hypothesis of model I and II indicate moderations of each profession i.e., (a) physicians, (b) IT professionals, (c) teachers.

\section{Problem Solution}

The empirical part of the research included an explanatory quantitative study in order to test the dependencies from the research models. To gather the required data, a survey was performed in a group of physicians, IT professionals, and teachers, using the computer-assisted web interviewing (CAWI) technique in the first quarter of 2017.

\subsection{Setting and Data}

The sample was selected in a purposive manner and was limited to knowledge workers working in Poland, initially defined as ones with a higher education degree and at least 10 years of working experience in their ${ }^{\circ}{ }^{\circ}$ ssion. Sample was divided in three subgroups of physicians, IT professionals and teachers. It was assumed that each subgroup should have the same characteristics due to the demographic variables demographic (age, sex), employment-related (work experience), and organisational characteristics (size, sector) in order to gather data allowing comparisons between professions. This was due to the lack of information on employment structure in all three professions, and simultaneously, it allowed for making intergroup comparisons.

The invitation to participate in the study was sent to 4.543 organizations from the medical, IT and educational sectors, assuming that the research respondents constitute the core staff in these organizations. In return, response rate was $8.8 \%$ of organizations, but there could not be more than three respondents from one organisation. Ultimately, data were gathered on 1189 subjects performing work at various levels of knowledge work, divided as follows: physicians $\mathrm{N}=411$, IT professionals $\mathrm{N}=427$, teachers $\mathrm{N}=351$.

Nearly all respondents held non-management positions $(\mathrm{N}=1131)$ and most were employed as specialists $(\mathrm{N}=905,76 \%)$. In the three groups, this percentage ranged between $85.6 \%$ (physicians) and $70.1 \%$ (teachers). Most respondents worked "overtime", i.e. more than 40 hours per week. This did not, however, apply to teachers, of whom 324 $(92.3 \%)$ worked the exact full time equivalent. Physicians worked the longest hours, with as many as 250 respondents $(60 \%)$ spending between 51 and 70 hours weekly at work. Roughly one in two physicians worked in multiple places $(\mathrm{N}=226,55 \%)$, similarly to IT professionals $(\mathrm{N}=250,58.5 \%)$. Nearly all physicians $(\mathrm{N}=400,97 \%)$ and all teachers worked under employment contracts. Among IT professionals, more than half $(\mathrm{N}=250,58.5 \%)$ worked under civil law contracts, and the remaining 
ones $(\mathrm{N}=177,41.5 \%)$ worked under employment contracts (see details in Table 1).

\subsection{Variables and Measures}

Knowledge transfer increases along with the number of individuals with whom one exchanges knowledge. In the research methodology applying network paradigm $[6 ; 14]$ used here, the egocentric knowledge networks are measured by their indegree centrality, i.e., the number of ties to a node, and out-degree centrality, i.e., the number of ties from a node $[1 ; 37 ; 64]$. This reflects the egocentric knowledge network and role of the recipient, and that of the provider, respectively.

The egocentric network of the knowledge recipient (ENKR) is measured by the numbers provided in response to the question: (1) How many people typically give you advice or valuable guidance when you do not know how to perform a new or difficult work-related task? (a measure of in-degree centrality). The egocentric network of the knowledge provider (ENKP) is measured by responses to the question: (2) How many people do you typically give advice or valuable guidance to when they do not know how to perform a new or difficult work-related task? (a measure of out-degree centrality).

Knowledge work (KW) and networking competence (NC) are latent variables, measured using reflective indicators - eight each for networking competence and knowledge work. For example, two reflective indicators of networking competence are: When I start a new task or project, I meet in person with everyone involved, When I am looking for a new or additional job, I call my acquaintances to ask if they know about any interesting offers for me. Final eight indicators were established as a measuring model based on confirmatory factor analysis $(\mathrm{CFI}=, 902$, RMSEA $=, 057, \mathrm{NFI}=, 878)$. Another two example indicators for knowledge work are: I perform routine tasks (reversed), When I work, I learn new things. Also analysing measurement model of knowledge work scale by confirmatory factor analysis brought results as follow: $\mathrm{CFI}=, 905$, RMSEA $=, 058, \mathrm{NFI}=, 885$. Achieved results confirm the scales reliability $[2 ; 32]$.

Responses on NC and KW were collected using a 7item scale, where $1=$ minimum at 7 maximum range. In the present analyses, mean reflective indicator values for each variable were used.

\subsection{Analysis and Results}

The collected quantitative data were used to test research models I and II and the associated hypotheses. IBM SPSS v. 25 software was used, with the PROCESS extension by F. Hayes. Model 59 was applied, as it is appropriate for the mediation and moderation strength and relationships between all the variables, i.e. knowledge work, networking competence, egocentric network of the knowledge provider, and egocentric network of the knowledge recipient.

In both knowledge transfer models, for the egocentric networks of the knowledge recipient (ENKR) and provider (ENKP), the association between knowledge work (KW) and networking competence (NC) moderated by profession has a good fit to data $(\mathrm{F}(3,1185), \mathrm{p}<.0001)$ and explains nearly half of the variance $\left(\mathrm{R}^{2}=.4930\right)$ with a beta regression coefficient of .3462. Other associations differ between the two models, and therefore, statistical analysis results will be provided separately for models I and II.

In the model for knowledge transfer in the egocentric network of the knowledge recipient, the direct impact of networking competence on the egocentric networks of the knowledge recipient is significant $(\mathrm{p}<.0001)$ and rather strong (beta $=.5624)$. In turn, the impact of knowledge work on the egocentric networks of the knowledge recipient size is not significant $(\mathrm{p}=.060)$ despite the regression coefficient value (beta=.2426). One may therefore assume that full mediation occurs in the model, consistently with hypothesis HI (1). Still, the moderation analyses for each profession indicate that dependencies in the model are strongly determined by profession (Table 1).

Table 1. Regression model I testing results, including mediation and moderation, for the egocentric network of the knowledge recipient

\begin{tabular}{|c|c|c|c|c|c|c|}
\hline path & Beta & SE & t- & & & \\
\hline$(\mathrm{KW}->\mathrm{NC}) \mathrm{x}$ profession & .3462 & .0342 & 10.123 & .000 & & \\
\hline (KW-->ENKR) $x$ profession & .2426 & .1289 & 1.8824 & .060 & & \\
\hline (NC--> ENKR $) x$ profession & .5624 & .1501 & 3.7470 & .000 & & \\
\hline & $\begin{array}{l}\text { direct } \\
\text { effect }\end{array}$ & SE & $\begin{array}{c}\text { t- } \\
\text { statistic }\end{array}$ & $\begin{array}{c}\text { p- } \\
\text { value }\end{array}$ & $\begin{array}{c}\text { indirect } \\
\text { effect }\end{array}$ & LLCI-ULCI \\
\hline & & ysician & & & & \\
\hline$(\mathrm{KW}->\mathrm{NC}) \times$ physicians & .0821 & .0477 & 1.7219 & .0853 & & $-.0114-.1756$ \\
\hline (KW-->ENKR) x physicians & .0050 & .1699 & .0296 & .9764 & & $-.3283-.3383$ \\
\hline (NC-->ENKR) $x$ physicians & .2950 & .1989 & 1.4830 & .1383 & & $-.0953-.6853$ \\
\hline$($ KW-->NC-->ENKR $) \times$ physicians & & & & & .0242 & $-.0044-.0705$ \\
\hline & IT $\mathbf{p}$ & ofessio & aals & & & \\
\hline$(\mathrm{KW}-->\mathrm{NC}) \times \mathrm{IT}$ professionals & .4282 & .0237 & 18.0816 & .000 & & $.3818-.4747$ \\
\hline (KW-->ENKR) x IT professionals & .2476 & .0969 & 2.5542 & .010 & & $.0574-.4378$ \\
\hline (NC-->ENKR) x IT professionals & .8574 & .1053 & 8.1452 & .000 & & $.6509-1.0640$ \\
\hline $\begin{array}{l}\text { (KW-->NC-->ENKR) x IT } \\
\text { professionals }\end{array}$ & & & & & .372 & $.2760-.4553$ \\
\hline & & eachers & & & & \\
\hline$(\mathrm{KW}-->\mathrm{NC}) \mathrm{x}$ teachers & .7744 & .0345 & 22.4614 & .000 & & $.7067-.8420$ \\
\hline (KW-->ENKR) $x$ teachers & .4902 & .1521 & 3.2219 & .001 & & $.1917-.7887$ \\
\hline$($ NC-->ENKR $) \times$ teachers & 1.4199 & .1663 & 8.5390 & .000 & & $1.0936-1.7461$ \\
\hline$(\mathrm{KW}->>\mathrm{NC}->>$ ENKR $) \times$ tea & & & & & 1.0995 & $.8290-1.3749$ \\
\hline
\end{tabular}

Analysis of direct and indirect impact on the egocentric network of the knowledge recipient among physicians showed that none of the analysed 
variables has a significant impact. The result for the direct impact of knowledge work on networking competence was .081 ( $\mathrm{p}=.0853)$, and on the egocentric networks of the knowledge recipient $.0050(p=.9764)$. No significance $(p=.1383)$ was found for the indirect effect (.2950) of networking competence on the egocentric network of the knowledge recipient. Considering mediation, the indirect impact of knowledge work on the egocentric network of the knowledge recipient is also insignificant due to the confidence interval found (-.0044-.0705). Thus, hypotheses HI (1a), HI (2a), HI (3a), and HI (4a) are all rejected.

In the studied group of IT professionals, the direct and indirect impact of all the analysed variables on knowledge transfer in the egocentric network of the knowledge recipient is significant, with differences in terms of strength. The strongest impact on the egocentric networks of the knowledge recipient was found in the case of networking competence (beta $=.8574, \mathrm{p}=.0001$ ). The impact of knowledge work was significant, but much weaker (beta $=.2476$, $\mathrm{p}=.010$ ). The indirect impact of knowledge work on the egocentric networks of the knowledge recipient, mediated by networking competence, is rather weak (indirect effect $=.372$, LLCI-ULCI $=.2760-.4553$ ), though stronger than the direct impact of knowledge work. The egocentric networks of the knowledge recipient growth among IT professionals depends mainly on their networking competence, with a much smaller impact of knowledge work. This supports hypotheses HI (1b), HI (2b), HI (3b), and HI (4b), indicating that IT professionals performing knowledge work must demonstrate networking competence to obtain knowledge from their contacts, as networking competence is the most significant factor in obtaining knowledge.

The system of dependencies among teachers is similar to that found among IT professionals, though the impact of knowledge work and networking competence is stronger: NC->ENKR: beta $=1.4199$, $\mathrm{p}<.0001)$ and KW->ENKR: beta $=.4902, \mathrm{p}=.001$. The mediation of networking competence between knowledge work and the egocentric networks of the knowledge recipient is also significant and strong among teachers (indirect effect $=1.0995$, LLCI$\mathrm{ULCI}=.8290-1.3749$ ), but less so than the direct impact of networking competence on the egocentric networks of the knowledge recipient. Thus, hypotheses $\mathrm{HI}(1 \mathrm{c}), \mathrm{HI}(2 \mathrm{c}), \mathrm{HI}(3 \mathrm{c})$, and $\mathrm{HI}(4 \mathrm{c})$ are confirmed, and the results indicate that the partial mediation model I of knowledge transfer is the strongest among teachers, compared to the other professions. Therefore, knowledge transfer to teachers from their contacts strongly depends on both their networking competence and knowledge work.

The mediation model does not apply to knowledge transfer in the egocentric network of the knowledge provider. The intermediate variable, networking competence, does not significantly affect the egocentric network of the knowledge provider (beta $=.2981, \mathrm{p}=.105$ ), undermining the assumption regarding mediation. The direct impacts of knowledge work on the egocentric network of the knowledge provider (beta $=.3981, \mathrm{p}=.012$ ) and on networking competence (beta $=.3462, \mathrm{p}<.0001$ ) are confirmed. As a result, hypothesis H II is partially confirmed, as it referred to a weak mediation of networking competence in knowledge transfer from the provider to other nodes of the egocentric network among all professionals in the sample.

Further analyses regarding differences between the professions with regard to the relevant dependencies indicate that no variables in model II are significant in the case of physicians. This means that no significant impact on knowledge transfer through the egocentric network of the knowledge provider growth was found either for knowledge work (beta $=.2643, p=.204$ ) or for networking competence, which was overall insignificant in model II, with no mediation (indirect effect=.3124, CI -.0081-.1094). Thus, hypotheses HII (1a), HII (2a), HII (3a), and HII (4a), regarding determinants of knowledge transfer from physicians to others, are all rejected.

IT professionals provide knowledge more as their knowledge work intensifies (beta $=.6625, \mathrm{p}<.0001$ ). Knowledge work also enhances networking competence (beta $=.4282, \mathrm{p}<.0001)$. Networking competence does not intensify knowledge transfer, neither directly nor through mediation with knowledge work (indirect effect $=.3124$, LLCI$\mathrm{ULCI}=.2029-.4280$ ), as its impact is weaker than the direct impact of knowledge work on the egocentric network of the knowledge provider size and knowledge transfer increase. So firstly, IT professionals provide more knowledge if their work has more characteristics of knowledge work, and secondly, networking competence is significant, but it limits knowledge transfer compared to the direct effect of knowledge work. This means that hypotheses HII (1b) and HII (2b) were fully confirmed, and hypothesis HII (4b) was partially confirmed. 
Table 2. Regression model testing results, including mediation and moderation, for the egocentric network of the knowledge provider

\begin{tabular}{|c|c|c|c|c|c|c|}
\hline path & $\begin{array}{c}\text { Beta } \\
\text { coefficient }\end{array}$ & SE & $\begin{array}{c}\text { t- } \\
\text { statistic }\end{array}$ & p-value & \multirow[b]{5}{*}{$\begin{array}{c}\text { indirect } \\
\text { effect }\end{array}$} & \multirow[b]{5}{*}{ LLCI-ULCI } \\
\hline$(\mathrm{KW}-->\mathrm{NC}) \mathrm{x}$ profession & .3462 & .0342 & 10.123 & .000 & & \\
\hline (KW-->ENKR) $\mathrm{x}$ profession & .3981 & .1578 & 2.5221 & 012 & & \\
\hline \multirow[t]{2}{*}{$(\mathrm{NC}-->\mathrm{ENKR}) \times$ profession } & .2981 & .1839 & 1.6214 & .105 & & \\
\hline & $\begin{array}{l}\text { direct } \\
\text { effect }\end{array}$ & SE & $\begin{array}{c}\mathbf{t}- \\
\text { statistic }\end{array}$ & p-value & & \\
\hline \multicolumn{7}{|c|}{ Physicians } \\
\hline$(\mathrm{KW}-->\mathrm{NC}) \mathrm{x}$ profession & .0821 & .0477 & 1.7219 & .088 & & $-.0114-.1756$ \\
\hline (KW-->ENKP) $\mathrm{x}$ profession & .2643 & .2081 & 1.2703 & .204 & & $-.1439-.6726$ \\
\hline$(\mathrm{KW}-->\mathrm{NC}-->\mathrm{ENKP}) \mathrm{x}$ profession & & & & & .0354 & $-.0081-.1094$ \\
\hline \multicolumn{7}{|c|}{ IT professionals } \\
\hline$(\mathrm{KW}-->\mathrm{NC}) \mathrm{x}$ profession & .4282 & .0237 & 18.0816 & .000 & & $.3818-.4747$ \\
\hline$(\mathrm{KW}-->\mathrm{ENKP}) \mathrm{x}$ profession & .6625 & .1187 & 5.5787 & .000 & & $.4295-.8954$ \\
\hline$(\mathrm{KW}-->\mathrm{NC}-->\mathrm{ENKP}) \mathrm{x}$ profession & & & & & .3124 & $.2029-.4280$ \\
\hline \multicolumn{7}{|c|}{ Teachers } \\
\hline$(\mathrm{KW}-->\mathrm{NC}) \mathrm{x}$ profession & .7744 & .0345 & 22.4614 & .000 & & $.7067-.8420$ \\
\hline$(\mathrm{KW}->\mathrm{NKP}) \times$ profession & 1.0606 & .1864 & 5.6909 & .000 & & .6949-1.4262 \\
\hline$(\mathrm{KW}-->\mathrm{NC}-->\mathrm{NKP}) \times$ profession & & & & & .7957 & $.4333-1.1723$ \\
\hline
\end{tabular}

Knowledge work increases teachers' networking competence (beta $=.7744, \mathrm{p}<.0001$ ), confirming hypothesis HII (1c). The direct impact of knowledge work on knowledge transfer in the egocentric network of the knowledge provider among teachers is much stronger $(1.0606, \mathrm{p}<.0001)$ than among IT professionals, which confirms HII (2c) and further explains the differences in knowledge transfer between professions. The mediating role of networking competence in knowledge transfer in the egocentric network of the knowledge provider among teachers is significant (indirect effect $=.7957$, LLCI-ULCI $=.7067-.8420$ ) but lower than direct effect. As to networking competence, it can also be involved in the transfer, but the resulting knowledge transfer is less intense than with the direct impact of knowledge work, which means that hypotheses HII (3c) and HII (4c) cannot be fully confirmed.

\section{Discussion}

\subsection{Scientific Contribution}

The above research procedure has provided the basis for answering the research questions and drawing conclusions that make up the scientific contribution of the present paper. These are as follows:

1. Knowledge transfer differs based on whether one obtains knowledge from others or provides it to them, as well as based on the quality of one's knowledge work and networking competence.

Knowledge transfer in the egocentric network of the knowledge recipient is determined by knowledge work, with mediation by networking competence. To obtain knowledge from others, the individual (ego) should perform knowledge work, i.e. use knowledge and create new knowledge within a diverse, autonomous, and creative work process. This is however not sufficient - they must also establish and maintain contacts required for their work. On the other hand, regardless of the quality of knowledge work performed, if an individual needs to acquire new knowledge, they cannot do this without networking competence, which is thus prerequisite for knowledge transfer. These findings emphasise the importance of relationships and proximity for obtaining knowledge and advice, consistently with recent reports by Mascia et al. [35], Kang, Kim [28], and Brennecke, Rank [9].

As to knowledge transfer in the egocentric network of the knowledge provider, it only depends on knowledge work. The establishment and maintenance of contacts with people who can assist one in performing knowledge work is not significant for the provision of one's knowledge to others. Knowledge transfer from the provider (ego) to recipients is possible whenever the provider has knowledge that is needed by others. Simply put, one cannot give what one does not have. Knowledge transfer from the provider tends to be responsive rather than proactive [68], as the latter would require seeking and keeping touch with individuals to whom one could provide knowledge. Though providers do perform high-quality knowledge work and share their knowledge with others, they do not apply their networking competence as a mechanism for maintaining reciprocity in the knowledge exchange network [12]. On the other hand, if they are willing to provide knowledge, they receive other benefits consistent with their values, in line with the social exchange theory [33].

2. Knowledge work and networking competence affect knowledge transfer in the egocentric networks of knowledge providers and recipients differently in each of the studied professions, i.e. physicians, IT professionals, and teachers.

Neither models were found significant for physicians. Thus, knowledge transfer, both in knowledge recipient and knowledge provider networks, is not determined by knowledge work or networking competence of physicians. Physicians obtain knowledge from their contacts and provide it to them, but without interrelations to knowledge work or networking competence. This is puzzling, considering that knowledge transfer in networks had been a major theme in previous research $[35 ; 67 ; 17$; 11]. This discrepancy might result from the broader context of health care system and physicians' working conditions in Poland, namely, labour 
shortages [59], excessively long working hours [36], and the fact that physicians do not tend to proactively establish new professional contacts in their networks and rather appreciate relations with closest co-workers: other physicians, supervisors, nurses and patients [4;18]. Work satisfaction assessed in various studies indicates that Polish physicians are at most moderately satisfied [18], which significantly decreases if they work for the public sector [47] but increases if they work abroad [4]. Relatively low level of work satisfaction might weaken the level of knowledge work which also covers organizational context which is said to be one of the biggest maladies of Polish healthcare system. Researched sample (55\%), as well as other studies and institutional statistic (53.1\%) [58] indicate that physicians perform multiple jobs which increases their work time even more. This fact might limit networking competence which, in order to be on a high level, requires additional time [65].

Conversely, work as a teacher entails stronger effects of the studied variables. Knowledge transfer in the egocentric networks of knowledge recipients is intensified by knowledge work and networking competence, both separately and in combination. In contrast to the general model, the one for teachers involves partial mediation. As in the general model for knowledge provision, however, knowledge transfer in the provider's network increases along with knowledge work. Teachers provide knowledge to more recipients when they work under conditions of autonomy, use advanced knowledge, solve complex tasks, and create new knowledge and innovations. Importantly, though, the direct and indirect effects of the studied variables in the case of teachers are very strong — stronger than in the entire group and the strongest among the three professions, which had not been expected at the design stage. This is even more interesting considering that the mean results for the three variables in the models, i.e. knowledge work, networking competence, and knowledge network, are lower than in the two other studied professions. Strong impact of knowledge work and networking competence on knowledge transfer in the teachers' egocentric network of the knowledge might be an effect of structure of in-degree centrality measure. As many as two fifths teachers (40.2\%) acquire knowledge from one person. Thus, each respondent, who acquires knowledge from more than one person works as a leverage effect for correlations between variable, hence do increasing impact of knowledge work and networking competence on knowledge transfer directed to teachers. That is why there are teachers, even though there were not many of them in the study sample, who represent key priorities for contemporary professional teachers implement "team leadership, instruction, networking and effective communication with parents and other stakeholders, improve their skills, collaborating with colleagues and parents, and thinking creatively about the challenges they face" [39], increase the levels of examined variables, as well as dependencies of the examined variables on the knowledge transfer.

Knowledge transfer in the egocentric networks of IT professionals has a similar structure to that found in the case of teachers, though with weaker effects. Still, IT professionals obtain knowledge from others through knowledge work and networking competence, both separately and in combination. As to knowledge transfer from IT professionals to others, it depends on knowledge work, but not on networking competence. Networking competence, knowledge work and egocentric knowledge networks among IT professionals are significantly higher than among physicians and teachers. IT professionals more often than representatives of other professions are satisfied with their job [47]. They declare the will as well for further training and development, which is usually realized using Internet; blogs and thematic portals are used by $80 \%$ of IT professionals, Internet forums by $54 \%$, on line courses by $48 \%$ and through the contact with co - workers (64\%) [46]. Therefore, they give involvement in gaining knowledge on every level of their knowledge work, as well as through establishing and maintaining contacts.

Teachers and IT professionals obtain more knowledge from others if they establish and maintain more contacts, and if they perform more knowledge work. In other words, they obtain new knowledge owing to their well-developed networking competence, their advanced knowledge work, or both.

\subsection{Implications}

In this article, the key problem in knowledge management, therefore, the knowledge transfer is analysed with the use of egocentric networks method.

This study investigates knowledge transfer in general sample as well in three different professions. A significant stake is the presentation of various dynamics of knowledge transfer, depending on whether knowledge is received from or provided to others. 
Knowledge needed for one's work can be obtained from others, especially if one actively establishes and maintains useful contacts. By developing networking competence, either on the initiative of the individual or of their employer, one can increase the knowledge resources available to fulfil one's needs in the egocentric network of knowledge recipient.

On the other hand, knowledge transfer to others in the egocentric network of knowledge providers develops as knowledge work increases. Knowledgeable professionals are not focused on networking in order to spread their knowledge. Thus, it is recommended for organisations to establish solutions for identifying key sources of knowledge in order to moderate the knowledge transfer. Otherwise knowledge flows would might be close up to clique of well introduced to knowledge provider. For example, knowledge centres can emerge wherever employees are allowed to autonomously tackle difficult tasks and seek innovative solutions which both require knowledge and create new knowledge resources. Those working there can then provide this knowledge to others, increasing access to knowledge resources. One important consideration is the need to protect organisational knowledge resources against unauthorised access. Employees' egocentric knowledge networks may span organisational boundaries, increasing the risk of knowledge leaks. It is therefore recommended that organisations establish practices regulating the extent of organisational knowledge that is shared.

Individuals who need to obtain knowledge from others find sources of this knowledge especially well when they have a high level of networking competence. If networking competence is not sufficiently developed, the creation of organisational or social knowledge centres or expert databases is worth considering. This could facilitate access to knowledge sources regardless of an employee's work characteristics or networking competence level.

Knowledge transfer in both directions requires trust, cooperation, and reciprocity. Therefore, it is recommended to develop a broader system of social exchange, so as to balance the roles of recipients and providers. An individual remaining in one role for an extended time may experience an imbalance in the exchange, which may result in termination of some contacts, especially those involving knowledge provision to others. Seeking the same advice from the same expert by multiple individuals should also be avoided, as the repetition of the same content to a number of recipients could be discouraging. This is why it is a good idea to create knowledge bases or to share relevant knowledge with a broader community when a new work-related challenge arises.

Presented recommendations might be applied to teachers and school principals as well as IT professionals and their employers but not directly for physicians. In case of physicians, and employing them organisations, the major recommendation is focused on improving work conditions building decent work and supporting socialisation with coworkers.

\subsection{Limitations and Indications for Future Research}

The reported findings have certain limitations, which on the one hand may prompt a discussion regarding their reliability, but on the other, could motivate further research.

The size of knowledge recipient and provider egocentric networks was declared by the respondents, as in the study by Halgin and Borgatti [25]. This means that the number of contacts with whom one exchanges knowledge was not verified by the alters - i.e. the other party in the knowledge transfer was not asked to confirm that they have actually taken part in said transfer.

Further studies could investigate knowledge transfer in both directions, though this would require a closed study population. Another potential area of research could involve the characteristics of alters the respondents transfer knowledge to or from. In the context of protecting organisational knowledge, it would be particularly interesting to investigate the extent to which knowledge transfer spans organisational boundaries.

Furthermore, the findings from the qualitative study only allowed for formulating general recommendations regarding the variability of egocentric networks in the studied professional groups. Though they supported the separate analyses performed in the three selected professions, a more in-depth exploration of knowledge transfer determinants in egocentric networks would be warranted.

\section{References:}

[1] Alba R. D., Taking stock of network analysis: A decade's results. Research in the Sociology of Organizations, Vol. 1, 1982, pp. 39-74.

[2] Arbuckle J.L., IBM SPSS Amos 22 User's Guide, 2013. 
[3] Aydogmus C., Millennial knowledge workers: The roles of protean career attitudes and psychological empowerment on the relationship between emotional intelligence and subjective career success, Career Development International, Vol. 24, No. 4, 2019, pp. 297314.

[4] Balins i P., Krajewski R., Opinie środowiska lekarskiego o pracy zawodowej, proteście lekarzy, cyfryzacji w ochronie zdrowia oraz o badaniach opinii środowiska. Podsumowanie najważniejszych wynikó , 2018 [Physicians opinions of work, physician's protest, healthcare digitization and about studies on physicians' community. Summarization of major findings, 2018]. Naczelna Izba Lekarska, https://nil.org.pl/uploaded_files/1575629771_o sai-sondaze-2018-raport-skrocony.pdf [access: August 2020].

[5] Borgatti S.P., Cross R., A., Relational View of Information Seeking and Learning in Social Networks, Management Science, Vol. 49, No. 4, 2003, pp 432-435.

[6] Borgatti S.P., Foster P., The Network Paradigm in Organizational Research: A Review and Typology, Journal of Management, Vol. 29, No. 6, 2003, pp. 991-1013.

[7] Borgatti S.P., Everett M.G., Johnson J.C., Analyzing Social Networks, Sage 2018.

[8] Brdulak J., Wiedza w zarzadzaniu przedsiębiorstwem: Koncepcja. Filary. Dobre praktyki [Knowledge in Managing Enterprise: Concept, Pillars, Good Practices], Oficyna Wydawnicza SGH, 2012.

[9] Brenncke J., Rank O., The firm's knowledge network and the transfer of advice among corporate inventors: A multilevel network study, Research Policy, Vol. 46, No. 4, 2017, pp. 768-783.

[10] Brinkley I., Fauth R., Mahdon M., Theodoropoulou S., Knowledge Workers and Knowledge Work, A Knowledge Economy Programme Report, The Work Foundation, 2009.

[11] Burt R.S., Meltzer D.O., Seid M., Borgert A., Chung, J.W., Colletti R.B., Dellal G., Kahn S.A., Kaplan H.C., Peterson L.A., Margolis P., What's in a name generator? Choosing the right name generators for social network surveys in healthcare quality and safety research, $B M J$ Quality and Safety, Vol. 21, 2012, pp. 9921000.

[12] Cross R., Sproull L., More Than an Answer: Information Relationships for Actionable
Knowledge, Organization Science, Vol. 15, No. 4, 2004, pp. 446-462.

[13] Cross R., Parker A., Prusak L., Borgatti S. P., Knowing what we know: Supporting knowledge creation and sharing in social networks, Organizational Dynamics, Vol. 20, 2001, pp. 100-120.

[14] Czakon W., Paradygmat sieciowy w naukach o zarządzaniu [Network pardigm in science of management], Przeglad Organizacji, Vol. 11, 2011, pp. 3-8.

[15] Czakon W., Sieci w zarzadzaniu strategicznym [Networks in Strategic Management], Wolters Kluwer, 2012.

[16] Davenport T., Thinking for a Living: How to Get Better Performance and Results from Knowledge Workers, Harvard Business Review Press, 2005.

[17] Di Vincenzo F., Mascia D., Knowledge development and advice networks in professional organizations. Knowledge Management Research \& Practice, Vol. 15, No. 2, 2017, pp. 201-213.

[18] Domagała A., Peña-Sánchez J.N. DubasJakóbc yk K., Satisfaction of Physicians Working in Polish Hospitals-A CrossSectional Study, International Journal of Environmental Research and Public Health, Vol. 15, No. 12, 2018, 2640.

[19] Drucker P., The age of discontinuity, Harper \& Row, 1968.

[20] Drucker P., Knowledge-worker productivity. The biggest challenge, California Management Review, Vol. 41, No. 2, 1999, pp. 79-94.

[21] Fenwick T., Knowledge workers in the in- between: network identities, Journal of Organizational Change Management, Vol. 20, No. 4, 2007, pp. 509-524.

[22] Forret M.L., Dougherty, T.S., Correlates of Networking Behavior and Professional Employees, Group and Organization Management, Vol. 23, No.3, 2001, pp. 283311.

[23] Gargiulo M., Ertug G., Galunic Ch., The Two Faces of Control: Network Closure and Individual Performance among Knowledge Workers, Administrative Science Quarterly, Vol. 54, No. 2, 2009, pp. 299-333.

[24] Gladwell M., Outliers: The Story of Success, Little, Brown and Company, 2008.

[25] Halgin D.S., Borgatti S.P., An Introduction to Personal Network Analysis and Tie Churn Statistics using E-NET, 2012, $\mathrm{http} / / /$ danhalgin.com/yahoo_site_admin/assets/ 
docs/Halgin_Borgatti_2012_Personal_Networ k_Analysis. $17673301 . \overline{p d f} \quad$ (Retrived: 17.02.2017).

[26] Hansen M.T., Nohria N., Tierney T., What's Your Strategy for Managing Knowledge?, Harvard Business Review, March-April, 1999, pp. 1-11.

[27] José Sousa M., Employees Perceptions about Knowledge Sharing Impacts on Organizational Practices, WSEAS Transactions on Business and Economics, Vol. 11, 2014 pp.718-724.

[28] Kang M., Kim B., Motivation, opportunity, and ability in knowledge transfer: a social network approach, Knowledge Management Research \& Practice, Vol. 15, No. 2, 2017, pp. 214-224.

[29] Kawa A., Matusiak M., Analiza relacji sieciowych $\mathrm{w}$ organizacji opartej na wiedzy [Analysis of network relationships in knowledge based organization], Problemy Zarzadzania, No. 14 (4:64), 2016, pp. 98-119.

[30] King W.R., He J., Knowledge Transfer, In D. Schwartz, D. Te'eni (Eds.), Encyclopedia of Knowledge Management, 2011, pp. 967-976, IGI Global. https://doi.org/10.4018/978-159904-931-1 [access: Match2019].

[31] Kleindorfer P.R., Wind Y. (Eds.), The network challenge, The Wharton School Publishing, Upper Saddle River, 2009.

[32] Konarski R. Modele równań strukturalnych. Teoria i praktyka [Structural equation models. Theory and practice], Wydawnictwo Naukowe PWN, (2009).

[33] Lazega E., Mounier B., Snijders T., Tubaro P., Norms, status and the dynamics of advice networks: A case study, Social Networks, Vol. 34, No. 3, 2012, pp. 323-332.

[34] Lin T-X., Lin H-Y., He Y-H., Du Y., The Social Dynamics of People Cooperation: A Study on On-line Knowledge Construction Networks, WSEAS Transactions on Business and Economics, Vol. 17, 2020, pp. 725-734.

[35] Mascia D., Pallotti F., Dandi R., Determinants of knowledge-sharing networks in primary care, Health Care Management Review, Vol. 43, No. 2, 2018, pp. 104-114.

[36] Ministerstwo Zdrowia. (2018), Ile pracują lekarze i lekarze dentyści w Polsce? [How long do physicians and dentist work?], https://nil.org.pl/uploaded_files/1575629838_m apy-zdrowia-2017-streszczenie-raportu.pdf [access: January 2020].

[37] Mizruchi M. S., Bunting D., Influence in Corporate Networks: An Examination of Four
Measures, Administrative Science Quarterly, Vol. 26, No. 3, 1981, pp. 475-489.

[38] Mors M.L., Rogan M., Lynch S.E., Boundary spanning and knowledge exploration in professional service firm, Journal of Professions and Organization, No. 5, Vol. 3, (2018, pp. 184-205.

[39] OECD (2020), TALIS 2018 Results (Volume II): Teachers and School Leaders as Valued Professionals, TALIS, OECD Publishing, Paris, https://doi.org/10.1787/19cf08df-en [access: August 2020].

[40] Okkonen J., Vuori V., Helander N., Enablers and restraints of knowledge work Implications by certain professions, Cogent Business \& Management, Vol. 5, 1, 2018.

[41] Park J.Y., Im I., Sung Ch.S., Is social networking a waste of time? The impact of social network and knowledge characteristics on job performance, Knowledge Management Research \& Practice, Vol. 15, No. 4, 2017, pp. 560-571.

[42] Paton S., Cutting through the confusion of contemporary work, Journal of Knowledge Management, Vol. 13, No. 1, 2009, pp. 88-97.

[43] Perry B.L., Pescosolido, B.A., Borgatti, S.P., Egocentric Network Analysis. Foundations, Methods and Models, Cambridge University Press, 2018.

[44] Phelps C., Heidl R. Wadhwa A., Knowledge, Networks, and Knowledge Networks: A Review and Research Agenda, Journal of Management, Vol. 38, No. 4, 2012, pp. 11151166.

[45] Probst G.J.B, Raub S., Romhardt K. Managing Knowledge: Building Blocks for Success, Willey, 2000.

[46] Raport z badania społeczności IT 2020 [Report of research among IT community 2020], https://bulldogjob.pl/it-report/2020 [access August 2020].

[47] Raport. Satysfakcja zawodowa Polakó 2016 [Report. Work Satisfaction of Poles 2016]. Sedlak\&Sedlak, https://badaniahr.pl/files/pdf/Satysfakcja\%20Za wodowa\%20Polakó \%202018\%20Sedlak\%20 $\& \% 20$ Sedlak.pdf [access: August 2020].

[48] Rawlings C.M., Loeb S., Effective Linking in a Principal Advice Network: A Conceptual Model and Exploratory Analysis, Stanford University, Center for Education Policy Analysis, 2010, https://pdfs.semanticscholar.org/35d9/4f4461e1 
5adc04dfa39654d1130ea11b9689.pdf [access: January 2019].

[49] Robins G.L., Pattison P.E., Wang P., Closure, connectivity and degree distributions: Exponential random graph $\left(\mathrm{p}^{*}\right)$ models for directed social networks, Social Networks, No. 31, 2009, pp.105-117.

[50] Salancik G. R., Wanted: A good network theory of organization, Administrative Science Quarterly, Vol. 40, No. 2, 1995, pp. 345-349.

[51] Schiuma G., Carlucci D., The Next Generation of Knowledge Management: Mapping-Based Assessment Models. In E. Bolisani, M. Handzic (Eds.), Advances in Knowledge Management: Knowledge Management and Organizational Learning, pp.197-214, Springer, Cham, 2015.

[52] Schiuma G., Moustaghfir K., Testa G., Knowledge transfer in vertical relationship: the case study of Val d'Agri oil district, Journal of Knowledge Management, Vol. 17, No. 4, 2013, pp. 617-636.

[53] Scott P., Knowledge workers: social, task and semantic network analysis, Corporate Communications: An International Journal, Vol. 10, No. 3, 2005, pp. 257-277.

[54] Seufert A., Krogh G., Bach A., Towards knowledge networking, Journal of Knowledge Management, Vol. 3, No. 3, 1999, pp. 180190.

[55] Shahbaznezhad H., Rashidirad M., Vaghefi I. A systematic review of the antecedents of knowledge transfer: an actant-object view, European Business Review, Vol. 31, No. 6, 2019, pp. 970-995.

[56] Sparrowe R.T., Liden R.C., Wayne S.J., Kraimer M. L. Social Networks and the Performance of Individuals and Groups, Academy of Management Journal, Vol. 44, No. 2, 2001, pp. 316-325.

[57] Stelmaszczyk M., Karpacz J., Związek międ y dzieleniem sie, wiedzą a innowacjami mediowany zaufaniem - poziom indywidualny [Interrelation between knowledge sharing and innovation mediated by trust - individual level], Prace Naukowe Uniwersytetu Ekonomicznego we Wrocławiu no 422, Wydawnictwo UE we Wrocławiu, 2016.

[58] Streiner D. L. Starting at the beginning: An introduction to coefficient alpha and internal consistency, Journal of Personality Assessment, Vol. 80, No. 1, 2003, 99-103.

[59] Sygut M., Niedzielski A., Liczba lekarzy w Polsce rośnie, problemem jest starzenie sie, adr
[The number of physicians is growing, but the problem is staff getting older]. Rynek Zdrowia, 2019, https://www.rynekzdrowia.pl/Finanse-izarzadzanie/Adam-Niedzielski-liczba-lekarzyw-Polsce-rosnie-problemem-jest-starzenie-siekadr,191461,1.html [access: August 2020].

[60] Szulanski G. The Process of Knowledge Transfer: A Diachronic Analysis of Stickiness, Organizational Behavior and Human Decision Processes, Vol. 82, 2000, pp. 9-27.

[61] Tobin D. The Knowledge-Enabled Organization, Amocon, 1998.

[62] Ujwary-Gil A., Organizational Network Analysis. Auditing Intangible Resources, Routledge, 2019.

[63] Wang C., Rodan S., Fruin M., Xu X., Knowledge networks, collaboration networks, and exploratory innovation, Academy of Management Journal, Vol. 57, 2014, pp. 484514.

[64] Wasserman S., Faust K. Social Network Analysis: Methods and Applications, Cambridge University Press, 1994.

[65] Wolff H.-G., Kim S., What Are the Costs of Networking? Developing and Testing Assumptions in Work and Nonwork Domains, Conference Paper 2012, https://www.researchgate.net/publication/3095 58195 [accessed: November 2016].

[66] Wolff H.-G., Moser K., Effects of networking on career success: a longitudinal study, Journal of Applied Psychology, Vol. 94, No.1, 2009, pp. 196-206.

[67] Zhang X., Liu S., Chen X., Gong Y., Social capital, motivations, and knowledge sharing intention in health Q\&A communities, Management Decision, Vol. 55, No. 7, 2017, pp. 1536-1557.

[68] Zhang X., Jiang J.Y., With whom shall I share my knowledge? A recipient perspective of knowledge sharing, Journal of Knowledge Management, Vol. 19, No. 2, 2015, pp. 277295. 
Contribution of Individual Authors to the Creation of a Scientific Article (Ghostwriting Policy)

Marzena Fryczyńs a - full contribution

Sources of Funding for Research Presented in a Scientific Article or Scientific Article Itself

This study was partially financed by the National Science Centre, Poland under grant no. 2015/17/B/HS4/02039.

\section{Creative Commons Attribution License 4.0}

(Attribution 4.0 International, CC BY 4.0)

This article is published under the terms of the Creative Commons Attribution License 4.0

https://creativecommons.org/licenses/by/4.0/deed.en US 